\title{
Lipoprotein Metabolism Influenced by Training-induced Changes in Human Skeletal Muscle
}

\author{
Bente Kiens* and Hans Lithell ${ }^{*}$ \\ *August Krogh Institute, University of Copenhagen, Copenhagen, Denmark; and ${ }^{\ddagger}$ Department of Geriatrics, University of Uppsala, \\ Uppsala, Sweden
}

\section{Abstract}

The influence of training-induced adaptations in skeletal muscle tissue on lipoprotein metabolism was investigated in six healthy men. The knee extensors were studied at rest and during exercise after 8 wk of dynamic exercise training of the knee extensors of one leg, while the other leg served as a control. The trained and nontrained thighs were investigated on different occasions.

In the trained knee extensors, muscle (m) lipoprotein lipase activity (LPLA) was $70 \pm 29 \%$ higher compared with the nontrained $(P<0.05)$, and correlated positively with the capillary density $(r=0.84)$.

At rest there was a markedly higher arteriovenous (A-V) VLDL triacylglycerol (TG) difference over the trained thigh, averaging $55 \mu \mathrm{mol} / \mathrm{liter}$ (range 30-123), than over the nontrained, averaging $30 \mu \mathrm{mol} /$ liter (4-72).

In addition to the higher LPLA and VLDL-TG uptake in the trained thigh, a higher production of HDL cholesterol (C) and $\mathrm{HDL}_{2}-\mathrm{C}$ was also observed $(P<0.05)$. Positive correlations between m-LPLA and A-V differences of VLDL-TG ( $r$ $=0.90 ; P<0.05)$ were observed only in the trained thigh.

During exercise with the trained thigh the venous concentration of $\mathrm{HDL}_{2}-\mathrm{C}$ was invariably higher than the arterial, and after $110 \mathrm{~min}$ of exercise a production of $88 \mu \mathrm{mol} / \mathrm{min}$ (54-199) of $\mathrm{HDL}_{2}-\mathrm{C}$ was revealed. Even though a consistent degradation of VLDL-TG was not found during exercise, the total production of HDL-C across the trained and nontrained thigh, estimated from A-V differences times venous blood flow for the whole exercise period, correlated closely with the total estimated degradation of VLDL-TG $(r=0.91)$.

At the end of $\mathbf{2} \mathrm{h}$ of exercise m-LPLA did not differ from the preexercise value in either the nontrained or the trained muscle.

We conclude that changes in the lipoprotein profile associated with endurance training to a large extent are explainable by training-induced adaptations in skeletal muscle tissue.

\section{Introduction}

Several studies have shown that the pattern of serum lipoproteins is related to the level of habitual physical activity. Results of longitudinal training studies strongly suggest that lipopro-

Address correspondence to Dr. B. Kiens, August Krogh Institute, Universitetsparken 13, DK-2100 Copenhagen, Ø, Denmark.

Received for publication 2 July 1986 and in revised form 12 July 1988.

J. Clin. Invest.

(c) The American Society for Clinical Investigation, Inc. 0021-9738/89/02/0558/07 \$2.00

Volume 83, February 1989, 558-564 tein changes can be induced in initially sedentary people by physical training in the absence of changes in body weight (1, 2). Furthermore, in a recent investigation of well-trained men with high serum levels of HDL a further increase in HDL was noted during 6 mo of enhanced training (3). The HDL fraction consists of two major components, $\mathrm{HDL}_{2}$ and $\mathrm{HDL}_{3}$. Very physically active people have higher $\mathrm{HDL}_{2}$ levels than sedentary subjects (4). After conditioning for $10 \mathrm{wk}$ a significant rise in $\mathrm{HDL}_{2}$-cholesterol $(\mathrm{C})^{1}$ concentrations was observed in initially sedentary men without weight changes, whereas $\mathrm{HDL}_{3}-\mathrm{C}$ tended to decrease (5). The mechanisms by which exercise and training influence the serum lipoprotein pattern have not been fully clarified. It is known, however, that $\mathrm{HDL}_{2}$ is derived from $\mathrm{HDL}_{3}$ during the hydrolysis of triacylglycerol (TG)-rich lipoprotein by the activity of lipoprotein lipase (LPLA) (6). Furthermore, higher LPLA is found in physically active than in sedentary men (7). Therefore, training-induced increase in muscle (m) LPLA might provide the functional basis for an increased formation of HDL-C in trained subjects.

Thus, the present study was designed to test the hypothesis that training-induced changes in skeletal muscle may contribute to the altered serum lipoprotein pattern. To approach this problem in man we chose to compare, in the same individual, the lipoprotein metabolism in the femoral quadriceps muscle of one leg after an 8-wk period of endurance dynamic knee extension exercise training with that in the contralateral, nontrained quadriceps muscle.

\section{Methods}

\section{Experimental model}

Subjects were seated on a specially designed ergometer that permitted exercise to be confined to the quadriceps femoris muscle group. (Fig. 1). This experimental model approaches an ideal model in man for studies of muscle alterations induced by physical training. The model allows direct measurements of blood flow and arteriovenous (A-V) differences over the contracting muscle, and muscle biopsies are easy to obtain. The knee extensor exercise is performed dynamically with 60 contractions $/ \mathrm{min}$. The contractions cause the lower part of the leg to move from 90 to $170^{\circ}$ flexion. A previously published paper details the design of the ergometer and documents the evidence that exercise is confined to the knee extensors (8).

\section{Subjects}

The study was performed on six healthy, normal men with an average age of $23 \mathrm{yr}$ (range 21-26) and average weight of $75 \mathrm{~kg}$ (range 69-81). Their maximal total body oxygen uptake $\left(\mathrm{VO}_{2}\right)$ during two-legged bicycle exercise averaged 3.65 liters/min (range $3.35-3.84$ ). The subjects

1. Abbreviations used in this paper: $\mathrm{A}-\mathrm{V}$, arteriovenous; $\mathrm{C}$, cholesterol; LPLA, lipoprotein lipase activity; m-LPLA, muscle LPLA; TG, triacylglycerol; V-A, venous-arterious; $\mathrm{VO}_{2}$, oxygen uptake; w.w., wet weight. 


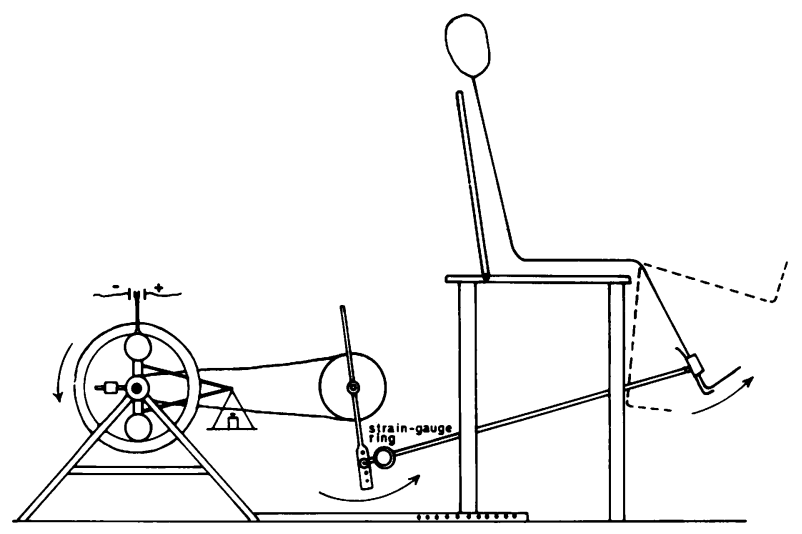

Figure 1. Modified Krogh bicycle ergometer for knee extension.

were all fully informed about the nature of the study and any risks involved before they volunteered to participate. A seventh subject participated in the study, but only muscle biopsies were taken in this subject.

The subjects were asked not to do any training other than the knee extensor exercises. They were initially familiarized with the model by practicing with both legs separately about five times. To determine the maximal work and peak $\mathrm{VO}_{2}$ for the knee extensors, a maximal test was performed with each leg separately. Total body $\mathrm{Vo}_{2}$ increased linearly with increasing work loads until an increase in work load caused a steeper increase in total body $\mathrm{VO}_{2}$. The sudden steeper rise in whole body $\mathrm{VO}_{2}$ is due to recruitment of extraneous muscles used to stabilize the body during knee extension. Total body $\mathrm{VO}_{2}$ at this point minus total body $\mathrm{VO}_{2}$ at rest was regarded as the peak $\mathrm{Vo}_{2}$ for the muscle studied.

\section{Training period}

Training consisted of knee extensor exercise with one leg during a total period of 8 wk. During the first 3 wk the subjects exercised $3 \mathrm{~d} / \mathrm{wk}$, increasing the duration of each session from 0.5 to $1.5 \mathrm{~h}$ during the 3-wk period. From week 4 they exercised $4 \mathrm{~d} / \mathrm{wk}$ for $2 \mathrm{~h}$ at each session and this was maintained during the final $5 \mathrm{wk}$. The work load was increased progressively in relation to the changes in maximal performance assessed every $2 \mathrm{wk}$, being kept at $65 \%$ of peak $\mathrm{Vo}_{2}$ for the knee extensors. In four subjects the right leg was trained and in three others the left leg.

\section{Experimental procedure}

In alternate subjects the trained or the nontrained leg was tested first. Dietary intake was controlled during days 1 and 2 (D-1 and D-2; see below). The controlled diet provided an average $37 \pm 5$ energy $\%$ of fat, $47 \pm 4$ energy $\%$ of carbohydrates, and $16 \pm 3$ energy $\%$ of proteins (mean \pm SE). The mean ratio of polyunsaturated to saturated fatty acids was $0.54 \pm 0.16$ and the total caloric intake was $11.7 \pm 2.3 \mathrm{MJ}$ per day. No alcohol was allowed.

$D-1$. No physical exercise was performed.

$D-2$. The subject arrived in the morning after an overnight fast of 10-12 h. After $20 \mathrm{~min}$ rest in the supine position blood was drawn from an arm vein while venous stasis was applied. A muscle biopsy was then taken from the lateral portion of one of the vastus femoris muscles $15 \mathrm{~cm}$ above the patella (9) for determination of LPLA and for histochemical analysis. The subject then performed knee extension exercise with the biopsied leg for $2 \mathrm{~h}$ at $\sim 65 \%$ of the maximal work capacity of the nontrained leg, which had been determined one week earlier. Pulmonary $\mathrm{VO}_{2}$ was measured during the work.

$D-3$. The subject arrived in the morning after an overnight fast of 10-12 h. Catheters were inserted into the femoral artery and vein of the test leg 2 and $4 \mathrm{~cm}$ distal to the inguinal ligament, respectively, and advanced centrally. A thermistor catheter (Edslab TD-probe; American Edwards Laboratories) was inserted through the venous catheter and advanced 12-15 cm anterogradely for measurement of blood flow. The subject then rested for $45 \mathrm{~min}$ in the supine position. After another $15 \mathrm{~min}$ of rest in the sitting position blood samples were drawn from the femoral artery and vein simultaneously. Thereafter, a muscle biopsy was taken from the lateral vastus muscle for determination of LPLA and histochemical analyses.

The subjects then repeated the knee extension exercise for $2 \mathrm{~h}$ at the same work level as on D-2. Arterial and venous blood samples were drawn simultaneously, and venous blood flow and pulmonary $\mathrm{VO}_{2}$ were measured during and at the end of the exercise period. The heart rate was monitored continuously. An inflatable cuff was placed just below the knee of the working leg and inflated to $280 \mathrm{mmHg}$ during each period of measurement $(2-2.5 \mathrm{~min})$ to exclude admixture of blood from the lower leg. Another biopsy was taken from the lateral vastus muscle of the quadriceps femoris at the end of exercise for determination of LPLA.

$4 \mathrm{~d}$ later the same protocol sequences were repeated on D-1, D-2, and D-3 with the other leg, with the same absolute work load.

\section{Analytical methods}

Blood analysis. Lipoproteins were separated by ultracentrifugation. A detailed description of the analyzing procedures for lipoproteins has been published previously (10). To minimize any transfer of lipids from VLDL and LDL to HDL during the preparative ultracentrifugation the following procedure was applied. $\mathrm{An} \mathrm{MgCl}_{2}$ phosphotungstate technique was used to precipitate the VLDL and LDL. The supernatant was ultracentrifuged (LKB-65; Beckman Instruments, Inc., Palo Alto, CA) at a density of 1.125 to separate $\mathrm{HDL}_{2}$ and $\mathrm{HDL}_{3}$.

VLDL in serum were isolated in the top fraction in a separate ultracentrifugation run at a density of 1.006. The VLDL fraction was analyzed for TG and C concentrations (see below) and also for free glycerol. To correct for contamination of free glycerol in the VLDL, the free serum glycerol was subtracted from the value for VLDL-TG. LDL were precipitated from the bottom fraction after the ultracentrifugation step and HDL were isolated in the supernatant after the precipitation.

TG and C concentrations were assayed in serum and in the different isolated lipoprotein subclasses using enzymatic methods (Boehringer Mannheim GmbH, Mannheim, FRG) in a Multistat III (Instrumentation Laboratory, Inc., Lexington, MA). The TG method is based on assay of glycerol after hydrolysis of the TG. The HDL subclasses $\mathrm{HDL}_{2}$ and $\mathrm{HDL}_{3}$ (see above) were assayed in quadruplicate and the mean values were used in the calculations. The analytical error (coefficient of variation) determined from 264 samples run in 19 series was 1.3 and $1.4 \%$ for TG and C analyses, respectively.

Insulin in serum was assayed by modified radioimmunoassay technique (Phadebas, Pharmacia Diagnostics AB, Uppsala, Sweden). Epinephrine and norepinephrine were measured by a single isotope-derivative assay (11).

All analyses of lipoproteins, insulin, epinephrine, and norepinephrine were done without knowing whether the samples were from the trained or nontrained leg.

Muscle analyses. A piece of the muscle biopsy specimen was immediately freed from blood and visible connective tissue, rapidly frozen in liquid nitrogen, and stored at $-80^{\circ} \mathrm{C}$ for subsequent biochemical analyses. The other part of the specimen was mounted in embedding medium, frozen in isopentane, cooled to its freezing point in liquid nitrogen, and then stored at $-80^{\circ} \mathrm{C}$ for subsequent histochemical analyses. LPLA was measured as described by Lithell and Boberg (12) with slight methodological modifications (13). The tissue was incubated in a heparin-containing medium with a serum-activated triolein emulsion with $\left[{ }^{3} \mathrm{H}\right]$ trioleate as trace substance (14). The release of $\left[{ }^{3} \mathrm{H}\right]$ oleic acid was used as a measure of LPLA. $1 \mathrm{nmol}$ of the fatty acid released per min was equal to $1 \mathrm{mU}$ of enzyme activity, and the activity is expressed per $\mathrm{g}$ wet weight (w.w.).

For histochemical analysis transverse sections $(10 \mu \mathrm{m})$ were cut with a microtome at $-20^{\circ}$. The amylase-periodic acid-Schiff method was used to visualize muscle capillaries (15). 
Blood flow was measured by the thermodilution technique. At rest a bolus of ice-cold saline was injected, but during exercise constant infusion of ice-cold saline was used as described by Andersen and Saltin (16). Pulmonary $\mathrm{VO}_{2}$ during rest and exercise was measured by collecting expired air in Douglas bags. A Tissot spirometer was used for volume analysis and the $\mathrm{O}_{2}$ and $\mathrm{CO}_{2}$ contents of the bags, collected during exercise, were determined with a paramagnetic (Taylor Servomex Limited, Crowborough, Sussex, UK) and infared (LB-2; Beckman Instruments, Inc.) system, respectively. The $\mathrm{O}_{2}$ and $\mathrm{CO}_{2}$ contents of the bags filled at rest were measured by the Scholander microtechnique. Heart rate was recorded on a Elema mingograph (Siemens Corp., Iselin, NY).

Statistics. Results are given in the following as mean values and ranges. For statistical analyses the paired Wilcoxon signed rank test, Friedman's two-way analysis of variance, and linear regression analysis were used.

\section{Results}

Muscle biopsies $(n=7)$

LPLA. In muscle biopsies taken on D-2 the mean resting LPLA was found to be $34.4 \mathrm{mU} / \mathrm{g}$ w.w. (16-78) in the nontrained muscle (Table I). In the trained muscle of six subjects LPLA was markedly higher compared with the nontrained muscle. In the seventh subject the LPLA was high in the nontrained muscle and was not higher in the trained muscle. Thus the mean of LPLA in the trained muscles was $49.3 \mathrm{mU} / \mathrm{g} \mathrm{w} . \mathrm{w}$. (36-63). The mean difference between nontrained and trained muscles was $70 \%(P<0.05)$.

Capillary density. A difference in capillary density was observed between the nontrained and the trained muscle. Thus, the number of capillaries surrounding each fiber averaged 1.82 (1.38-2.22) in the nontrained muscle but $2.25(1.87-2.53)$ in the trained muscle $(P<0.05)$. There were $343(276-401)$ capillaries $/ \mathrm{mm}^{2}$ in nontrained and $417(350-495) / \mathrm{mm}^{2}$ in trained muscle $(P<0.05)$. Comparing $m$-LPLA and the capillary density, increased m-LPLA was correlated with an increased capillary density ( $r=0.85$; Fig. 2$)$.

Peak $\mathrm{VO}_{2}$. The $\mathrm{Vo}_{2}$ of the knee extensors (peak $\mathrm{Vo}_{2}$ ) was determined by subtracting resting total body $\mathrm{VO}_{2}$ from exercising total body $\mathrm{Vo}_{2}$. Peak $\mathrm{Vo}_{2}$ in the nontrained muscle averaged $0.870(0.780-0.950)$ liters $/ \mathrm{min}$, whereas in the trained muscle it averaged $1.06(0.920-1.14$ liters $/ \mathrm{min} ; P$ $<0.05)$.

\section{Resting study}

The arterial VLDL-TG concentration in the nontrained muscle was $361 \mu \mathrm{mol} / \mathrm{liter}(236-584)$ and $360 \mu \mathrm{mol} / \mathrm{liter}$

Table I. m-LPLA, Mean \pm SE of Seven Subjects

\begin{tabular}{lcc}
\hline & Nontrained & Trained \\
\hline & $m U / g w . w$. & $m U / g w . w$. \\
D-2 & $34.4 \pm 8.2$ & $49.3 \pm 3.6^{*}$ \\
D-3 & & \\
Before exercise & $36.7 \pm 7.4$ & $49.6 \pm 6.0$ \\
After exercise & $36.7 \pm 8.1$ & $49.4 \pm 6.3$
\end{tabular}

* Differences between nontrained and trained muscle $(P<0.05)$. The values were obtained in the morning at rest on D-2 and again in the morning on D-3 at rest and after $2 \mathrm{~h}$ of exercise in nontrained and trained muscle (vastus lateralis muscle).
Figure 2. LPLA related to the capillary density. Individual values for nontrained $(0)$ and endurance-trained (๑) quadriceps femoris muscle are given $(r$ $=0.85$ ). Determination of both values was made on tissue from the same muscle biopsy sample taken on D-2 in resting, fasting subjects.

(210-650) in the trained muscle. The A-V VLDL-TG difference over the nontrained muscle amounted to $30 \mu \mathrm{mol} / \mathrm{liter}$ (4-72), but was markedly higher over the trained muscle, averaging $55 \mu \mathrm{mol} /$ liter (30-123) (Table II).

The arterial concentration of HDL-C averaged 1.00 $\mathrm{mmol} / \mathrm{liter}(0.83-1.20)$ and $1.04 \mathrm{mmol} / \mathrm{liter}(0.74-1.34)$ in the nontrained and trained muscle, respectively. Mean femoral vein concentration of HDL-C was $1.01 \mathrm{mmol} / \mathrm{liter}(0.83-1.20)$ in the nontrained and $1.10 \mathrm{mmol} / \mathrm{liter}(0.80-1.36)$ in the trained muscle. Thus a nonconsistent venous-arterious (V-A) HDL-C difference was found over the nontrained muscle ( 10 $\mu$ mol/liter $)(-30-+50)$, whereas a consistent positive $\mathrm{V}-\mathrm{A}$ difference of $\mathrm{HDL}-\mathrm{C}$ was obtained over the trained muscle averaging $53 \mu \mathrm{mol} / \mathrm{liter}(20-110)(P<0.05$, Table II). The arterial concentration of $\mathrm{HDL}_{2}-\mathrm{C}$ in the nontrained muscle averaged $324 \mu \mathrm{mol} / \mathrm{liter}$ (231-440) and no consistent A-V HDL 2 differences were noted. In the trained muscle the arterial $\mathrm{HDL}_{2}-\mathrm{C}$ concentration was $362 \mu \mathrm{mol} / \mathrm{liter}(230-630)$ and was not different from the arterial concentration in the nontrained muscle. However, in the trained muscle the concentration of $\mathrm{HDL}_{2}-\mathrm{C}$ was markedly higher in the femoral vein compared with the artery, averaging $400 \mu \mathrm{mol} / \mathrm{liter}$ (291-500). Thus, over the trained muscle the $\mathrm{V}$-A difference in $\mathrm{HDL}_{2}-\mathrm{C}$ was 38 $\mu \mathrm{mol} /$ liter (10-73), which was significantly higher than that over the nontrained muscle $(P<0.05)$ (Table II, Fig. 3$)$.

The arterial LDL-C concentration was $2.79 \mathrm{mmol} / \mathrm{liter}$ (1.67-3.33) and $2.81 \mathrm{mmol} / \mathrm{liter}(1.66-3.48)$ in the nontrained and trained muscle, respectively. The $\mathrm{V}$-A difference in this variable was $113 \mu \mathrm{mol} / \mathrm{liter}(90-160)$ over the nontrained muscle, but lower over the trained muscle, averaging 92 $\mu$ mol/liter (20-150) (Table II).

The mean resting femoral venous blood flow was 0.620 liters/min in both legs. The uptake of VLDL-TG calculated from arterial minus venous VLDL-TG concentration times plasma flow averaged $8 \mu \mathrm{mol} / \mathrm{min}$ in the resting nontrained muscle and $19 \mu \mathrm{mol} / \mathrm{min}$ in the resting trained muscle. The mean formation of $\mathrm{HDL}_{2}-\mathrm{C}$ in plasma, calculated as arterial minus venous $\mathrm{HDL}_{2}-\mathrm{C}$ content times plasma flow was 15 $\mu \mathrm{mol} / \mathrm{min}$ in the trained muscle at rest, but was not significantly different from zero in the nontrained muscle.

At rest no significant correlations were found over the nontrained leg between $\mathrm{m}-\mathrm{LPL}$ activity and A-V differences of VLDL-TG $(r=-0.31)$, between m-LPL activity and A-V differences of $\mathrm{HDL}-\mathrm{C}$ and $\mathrm{HDL}_{2} \mathrm{C}(r=0.13$ and $r=-0.13$, respectively), or between A-V differences of VLDL-TG and HDL-C $(r=0.13)$. However, over the trained leg a positive correlation was found between $\mathrm{m}-\mathrm{LPL}$ activity and A-V differences of VLDL-TG $(r=0.71)$, between m-LPL activity and 
Table II. Resting Values for Concentrations of Lipoproteins in Femoral Arterial and Venous Serum in the Nontrained and Trained Muscle, mean \pm SE of Six Subjects

\begin{tabular}{|c|c|c|c|c|c|c|}
\hline & \multicolumn{3}{|c|}{ Nontrained muscle } & \multicolumn{3}{|c|}{ Trained muscle } \\
\hline & A & $\mathrm{v}$ & $(\mathrm{A}-\mathrm{V})$ & A & $\mathbf{v}$ & $(A-V)$ \\
\hline HDL-C (mmol/liter) & $1.00 \pm 0.08$ & $1.01 \pm 0.05$ & $-0.010 \pm 0.01$ & $1.04 \pm 0.07$ & $1.10 \pm 0.07$ & $-0.053 \pm 0.016^{*}$ \\
\hline $\mathrm{HDL}_{2}-\mathrm{C}(\mu \mathrm{mol} /$ liter $)$ & $324 \pm 28$ & $322 \pm 26$ & $2 \pm 7$ & $362 \pm 57$ & $400 \pm 53$ & $-38 \pm 6^{*}$ \\
\hline LDL-C (mmol/liter) & $2.79 \pm 0.24$ & $2.91 \pm 0.24$ & $-0.113 \pm 0.01$ & $2.81 \pm 0.26$ & $2.90 \pm 0.28$ & $-0.092 \pm 0.03$ \\
\hline VLDL-C ( $\mu \mathrm{mol} /$ liter $)$ & $214 \pm 40$ & $247 \pm 60$ & $-34 \pm 12$ & $186 \pm 39$ & $171 \pm 33$ & $14 \pm 11$ \\
\hline VLDL-TG $(\mu \mathrm{mol} /$ liter $)$ & $361 \pm 66$ & $330 \pm 72$ & $30 \pm 12$ & $360 \pm 50$ & $305 \pm 56$ & $55 \pm 17^{*}$ \\
\hline
\end{tabular}

* Differences between nontrained and trained $(P<0.05)$.

A-V differences of HDL-C $(r=0.80, P<0.05)$ and $\mathrm{HDL}_{2}-\mathrm{C}(r$ $=0.83, P<0.05)$, and between A-V differences of VLDL-TG and HDL-C $(r=0.90, P<0.05)$.

\section{Exercise study}

Total body $\mathrm{VO}_{2}$ averaged $795 \mathrm{ml} / \mathrm{min}(623-1,075) 10 \mathrm{~min}$ after the start of exercise with the nontrained muscle and increased toward the end of the 2 -h work period to $890 \mathrm{ml} / \mathrm{min}$ (648-1,212) $(P<0.05)$. During exercise with the trained muscle total body $\mathrm{VO}_{2}$ was $807 \mathrm{ml} / \mathrm{min}(583-961)$ at $10 \mathrm{~min}$ and remained at that level for the rest of the exercise period.

The heart rate averaged 110 beats/min (88-141) after 10 min exercise, with both the nontrained and the trained muscle. During the remaining period of exercise with the nontrained muscle it increased continuously, averaging 128 beats/min (100-160) at $110 \mathrm{~min}$, whereas during exercise with the trained muscle it remained constant.

The femoral venous blood flow remained constant during exercise. In the exercising nontrained leg the blood flow was 5.51 liters/min, but in the exercising trained leg it was lower, averaging 4.65 liters $/ \mathrm{min}(P<0.05)$.

In the nontrained leg the arterial concentration of VLDLTG was $417 \mu \mathrm{mol} / \mathrm{liter}(220-1,168)$ after $60 \mathrm{~min}$ of exercise and increased to $495 \mu \mathrm{mol} / \mathrm{liter}(266-1,116)$ at $110 \mathrm{~min}$. In the exercising trained leg the arterial concentration of VLDL-TG increased to $392 \mu \mathrm{mol} / \mathrm{liter}(180-655)$ at $60 \mathrm{~min}$ and to 439 $\mu \mathrm{mol} /$ liter $(210-761)$ at $110 \mathrm{~min}(P<0.05)$. Small but inconsistent A-V differences of VLDL-TG were found over the exercising nontrained and trained muscle.

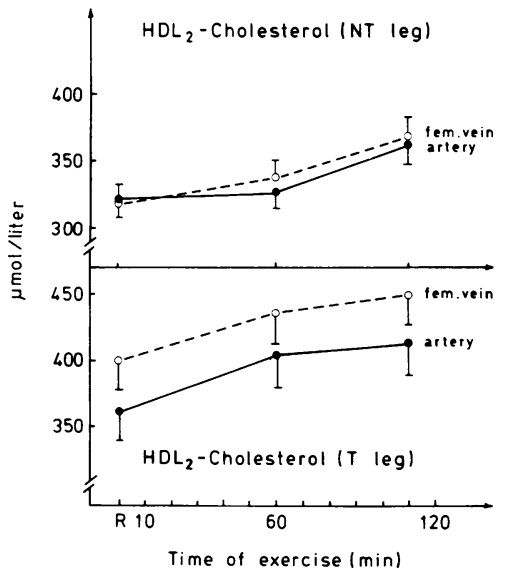

Figure 3. Mean values of $\mathrm{HDL}_{2}-\mathrm{C}$ concentration in femoral arterial and venous blood in the nontrained $(N T)$ and trained $(T)$ legs at rest $(R)$ and during exercise with the knee extensors of one leg.
During exercise the arterial concentration of HDL-C increased nonsignificantly from resting values in both the nontrained (1.06 mmol/liter [0.89-1.19] at $60 \mathrm{~min}$ and 1.05 $\mathrm{mmol} / \mathrm{liter}[0.89-1.19]$ at $110 \mathrm{~min})$ and trained thigh $(1.08$ $\mathrm{mmol} /$ liter [0.83-1.28] at $60 \mathrm{~min}$ and $1.07 \mathrm{mmol} / \mathrm{liter}$ [0.831.25 ] at $110 \mathrm{~min})$.

Positive V-A HDL-C concentration differences were observed over both the exercising nontrained (12 $\mu \mathrm{mol} / \mathrm{liter}$ [-60-40] at $60 \mathrm{~min}$ and $18 \mu \mathrm{mol} / \mathrm{liter}[-40-70]$ at $110 \mathrm{~min}$ ) and trained thigh $(10 \mu \mathrm{mol} / \mathrm{liter}[0-30]$ at $60 \mathrm{~min}$ and 30 $\mu \mathrm{mol} /$ liter [10-80] at $110 \mathrm{~min}$ ) except in one subject in the nontrained situation, where negative V-A HDL-C concentrations were found. Difference in production between the nontrained and trained thigh were not significant.

At rest the arterial concentration of $\mathrm{HDL}_{2}-\mathrm{C}$ was similar on the day when the nontrained muscle was studied $(324 \mu \mathrm{mol} /$ liter) and on the day the trained muscle was studied (362 $\mu \mathrm{mol} /$ liter). A small, nonsignificant increase was observed during the exercise period in both situations.

No consistent $\mathrm{V}-\mathrm{A}$ differences in $\mathrm{HDL}_{2}-\mathrm{C}$ were observed over the exercising nontrained muscle, whereas in the exercising trained muscle there was a mean V-A difference at $60 \mathrm{~min}$ of $30 \mu \mathrm{mol} /$ liter $(0-60)$ and $34 \mu \mathrm{mol} /$ liter at $110 \mathrm{~min}(20-80)$ (Fig. 3).

Before exercise the LPLA was $36.7 \mathrm{mU} / \mathrm{g}$ w.w. in the nontrained muscle and remained unchanged at the end of the exercise period $(36.7 \mathrm{mU} / \mathrm{g}$ w.w.). In the trained muscle the preexercise LPLA value averaged $49.3 \mathrm{mU} / \mathrm{g}$ w.w. and no change was observed at the end of exercise ( $49.6 \mathrm{mU} / \mathrm{g} \mathrm{w.w.)}$ (Table I).

Hormones. The mean arterial insulin concentrations at rest were similar on the days of experiments with the nontrained (7.8 $\mathrm{mU} /$ liter) and the trained muscle ( $7.5 \mathrm{mU} /$ liter) (Table III). During exercise the arterial insulin level decreased continuously to $3.7 \mathrm{mU} / \mathrm{liter}$ in the nontrained and $4.4 \mathrm{mU} / \mathrm{liter}$ in the trained muscle at $110 \mathrm{~min}$ (Table III).

The arterial concentrations of epinephrine were similar on the days of experiments with the nontrained and trained muscle at rest $(0.12$ and $0.11 \mathrm{ng} / \mathrm{ml}$, respectively; Table III). Changes from resting values were not observed during exercise with either muscle category (Table III). The resting arterial norepinephrine concentrations were also similar on the days of experiment with the nontrained $(0.38 \mathrm{ng} / \mathrm{ml})$ and the trained muscle $(0.33 \mathrm{ng} / \mathrm{ml})$ (Table III). $10 \mathrm{~min}$ after exercise with the nontrained muscle, arterial norepinephrine had risen to 0.46 $\mathrm{ng} / \mathrm{ml}(P<0.05)$ and an insignificant increase followed during 
Table III. Mean Values $\pm S E$ of Norepinephrine (NE), Epinephrine (E), and Insulin in Femoral Arterial Blood during $2 h$ of Exercise with the Trained (T) and Nontrained (NT) Thigh $(n=6)$

\begin{tabular}{|c|c|c|c|c|c|c|}
\hline \multirow[b]{2}{*}{ Time } & \multicolumn{2}{|c|}{ Arterial NE } & \multicolumn{2}{|c|}{ Arterial E } & \multicolumn{2}{|c|}{ Arterial insulin } \\
\hline & $\mathrm{T}$ & NT & $\mathrm{T}$ & NT & $T$ & NT \\
\hline $\min$ & \multicolumn{2}{|c|}{$n g / m l$} & \multicolumn{2}{|c|}{$n g / m l$} & \multicolumn{2}{|c|}{ mU/liter } \\
\hline \multirow[t]{2}{*}{ Rest } & 0.33 & 0.38 & 0.11 & 0.12 & 7.8 & 7.5 \\
\hline & $(0.09)$ & $(0.02)$ & $(0.05)$ & $(0.03)$ & $(0.9)$ & (1.2) \\
\hline \multirow[t]{2}{*}{10} & $0.37^{*}$ & 0.46 & 0.12 & 0.14 & & \\
\hline & $(0.04)$ & $(0.03)$ & $(0.03)$ & $(0.02)$ & & \\
\hline \multirow[t]{2}{*}{60} & $0.45^{*}$ & $0.54^{*}$ & 0.13 & 0.14 & $5.5^{*}$ & $5.1^{*}$ \\
\hline & $(0.05)$ & $(0.05)$ & $(0.03)$ & $(0.02)$ & $(0.7)$ & (1.4) \\
\hline \multirow[t]{2}{*}{110} & $0.47^{*}$ & $0.61^{*}$ & 0.14 & 0.19 & $4.4^{*}$ & $3.7^{*}$ \\
\hline & $(0.05)$ & $(0.05)$ & $(0.02)$ & $(0.02)$ & $(0.8)$ & $(0.6)$ \\
\hline
\end{tabular}

* Difference compared with resting levels $(P<0.05)$.

the remaining exercise period. During exercise with the trained muscle an increase to $0.37 \mathrm{ng} / \mathrm{ml}$ was found at $10 \mathrm{~min}(P$ $<0.05)$ and a further increase to $0.45 \mathrm{ng} / \mathrm{ml}$ at $60 \mathrm{~min}(P$ $<0.05$ ), and the value then remained at that level (Table III).

Training effect on $H D L$. To elucidate the question of whether training with one muscle group caused systemic effects on lipoprotein concentrations, blood was sampled from an arm vein both before and after the 8-wk training period. Initially the HDL-C concentration averaged $1.16 \mathrm{mmol} / \mathrm{liter}$ $(0.88-1.46)$ and at the end of the training period it was 1.25 $\mathrm{mmol} / \mathrm{liter}(0.91-1.60)$. Thus, the concentration increased during the training period in all subjects by an average of $8 \%$ $(4-12 \% ; P<0.05)$. Compared with values obtained in the femoral artery and vein, arm vein values were slightly higher, probably due to the effect of venous stasis.

\section{Discussion}

In the present study we have investigated the influence of $8 \mathrm{wk}$ of dynamic exercise training of one quadriceps femoris muscle on muscle lipoprotein metabolism at rest and during exercise, using the nontrained contralateral muscle as control. The major findings were a training-induced increase in m-LPLA and a significant formation of $\mathrm{HDL}_{2}-\mathrm{C}$ in trained muscle but not in nontrained muscle.

An increase in the activity of skeletal m-LPLA by 47\% was previously observed after a period of physical training in nonobese, healthy men (17). In that study, however, the state of nutrition, which may significantly influence LPLA (18-20), was not controlled. In the present dietary-controlled study the $\mathrm{m}$-LPLA was $70 \%$ higher in the trained muscle compared with the nontrained muscle of the same individual, which may at least partly be the result of the increase in capillary density in the trained muscle. The physiological site of LPLA is the luminal surface of the capillary endothelium, where the enzyme is bound to the endothelial cell surface. In the trained muscle the increased number of capillaries around each fiber type compared with the nontrained muscle provides more binding sites for the enzyme. Moreover, LPLA correlated with the capillary density (Fig. 2), which further supports the idea of a causal relationship between capillary density and LPLA. In the present study both were determined in tissue from the same biopsy sample. This was not the case in an earlier study, which probably explains why such a relationship was not found then (17).

It has been suggested that the breakdown of VLDL may contribute to the formation of $\mathrm{HDL}_{2}$ in the circulation. The primary HDL particle (nascent HDL) is produced in the intestine and liver, but immediately after its delivery to the circulation it is transformed to $\mathrm{HDL}_{3}$. Upon assimilation of phospholipids, C, and apoproteins from degraded VLDL, the $\mathrm{HDL}_{3}$ is transformed to particles designated $\mathrm{HDL}_{2}(6)$. Since the degradation of TG-rich particles is largely dependent upon the LPLA in peripheral tissues $(21,22)$, an increase in tissue LPLA is expected to result in transference of an increased amount of surface material to HDL in the plasma compartment. The question arises whether the formation of $\mathrm{HDL}_{2}-\mathrm{C}$ in the trained leg can be ascribed to transference of surface material from VLDL-TG as a result of LPLA. Such a contention is in agreement with the finding of significantly larger A-V differences for VLDL-TG at rest in trained muscle compared with nontrained, while significant formation of HDL-C and $\mathrm{HDL}_{2}-\mathrm{C}$ was only observed in trained muscle (Table II). It also agrees with the finding of a training-induced increase in $\mathrm{m}$ LPLA (Table I). Still, it might seem strange that no consistent formation of HDL-C and $\mathrm{HDL}_{2}-\mathrm{C}$ was observed in the nontrained leg in spite of significant degradation of VLDL-TG (Table II). However, it is interesting to note that at rest a correlation between VLDL-TG degradation and m-LPLA as well as between LPLA and HDL-C and $\mathrm{HDL}_{2}-\mathrm{C}$ formation was obtained only in trained muscle. Furthermore, a significant correlation between degradation of VLDL-TG and formation of HDL-C was only found in trained and not in nontrained muscle at rest. Since arterial concentrations of insulin, catecholamines, and VLDL-TG as well as blood flow were similar when the trained and nontrained muscles were studied at rest, the above-mentioned correlations suggest that in addition to the training-induced increase in m-LPLA as measured in vitro, training may also have elicited qualitative changes in LPLA. Such qualitative changes could explain the apparent difference in expression of LPLA in vivo in the trained and nontrained muscle. Obviously, the above described differences in in vivo expression of LPLA could also be ascribed to a diminished inhibition of LPLA in the trained compared with the nontrained muscle. Support for such a contention may be found in a study by Olivecrona and Bengtsson (23), who suggest that when lipoproteins encounter LPL at the endothelium, lipid hydrolysis is initially very rapid and the lipolytic products are rapidly and efficiently used by the tissue cells, probably after removal from the site of hydrolysis by lateral diffusion in the cell membrane (24). However, when the capacity for product use in the tissue is exceeded, hydrolysis slows down primarily as a result of product inhibition of LPLA (22). The capacity for using fatty acids as an energy source obviously was improved in trained muscle, as the activity of the enzyme $\beta$-OH-acyl CoA-dehydrogenase, which is needed for $\beta$-oxidation of fatty acids was $40 \%$ higher in trained than in nontrained muscle (25). Moreover, the diffusion distances decreased in trained muscle as judged by the increase in capillary density. Thus, in trained muscle the existence of a greater potential for removal and use of fatty acids from the site of TG hydrolysis makes it likely that in vivo LPLA is less inhibited 
than in nontrained muscle, in turn accounting for the observed increased femoral venous concentration of $\mathrm{HDL}_{2}-\mathrm{C}$ (and HDL-C) in trained compared with nontrained muscle.

During exercise a significant formation of $\mathrm{HDL}_{2}-\mathrm{C}$ and HDL-C was only detectable in the trained leg, but significant A-V differences for VLDL-TG were measurable neither in trained nor in nontrained muscle. Probably due to the much higher blood flow during exercise than rest, which in turn decreases capillary transit time drastically, VLDL-TG differences were not consistently detectable. However, in an effort to obtain a rough estimate of total leg degradation of VLDLTG during exercise, the area under the arterial and venous concentration curves was integrated from 0 to $110 \mathrm{~min}$ of exercise. The difference between these areas multiplied by the plasma flow thus represents an estimate of the total leg degradation of VLDL-TG. Similar calculations were performed for total HDL-C formation. The estimates for VLDL-TG degradation and for formation of total HDL-C using values from both trained and nontrained legs correlated closely $(r=0.91$; Fig. 4). This correlation strengthens the probability that HDL-C formation was due to hydrolysis of VLDL-TG during exercise as well.

During exercise diminished product inhibition of LPL could be a factor explaining why $\mathrm{HDL}_{2}-\mathrm{C}$ formation was found only across the trained muscle. Apart from the traininginduced increased capacity for fatty acid oxidation and the possibility that increased capillarization improved diffusion conditions, the training-induced increased capillary density has other possible effects. Thus, the larger capillary density in conjunction with the lower blood flow in the trained muscle during exercise implies that the mean capillary transit time was longer in trained than in nontrained muscle. This may be of importance for the transport of gas and substrates within the muscle, but it also appears likely that a longer mean transit time may be crucial for the contact between lipoprotein particles and LPL, and thus for the formation of HDL. Such factors may help to explain why $\mathrm{A}-\mathrm{V}$ differences in $\mathrm{HDL}_{2}-\mathrm{C}$ and HDL-C were found only in the trained muscle during exercise.

Previous studies have shown that a single bout of whole body exercise results in increased m-LPLA and the response seems to be related more to the duration than to the intensity of exercise $(26,27)$. It may also be related to the status of intramuscular substrate levels $(28,29)$. In a previous study it was found that during days of heavy exercise afternoon values of LPLA were significantly higher than morning values (30), and this exercise-induced increase appeared to persist for at least $12 \mathrm{~h}$. In the present study no changes in LPLA were found on the morning after $(18 \mathrm{~h}) 2 \mathrm{~h}$ of submaximal exercise was performed (Table I), either in trained or in nontrained

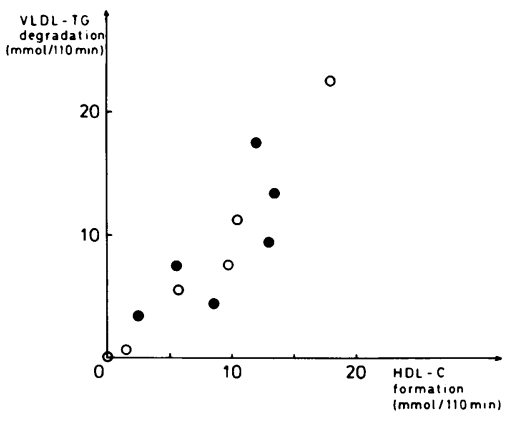

Figure 4. Total VLDLTG degradation during $110 \mathrm{~min}$ of exercise $(\mathrm{mmol} / 110 \mathrm{~min})$ related to total HDL-C formation during $110 \mathrm{~min}$ of exercise $(\mathrm{mmol} / 110$ min). Individual values for nontrained (o) and trained (๑) thigh are given $(r=0.91)$. muscle. Moreover, m-LPLA was not altered immediately after $2 \mathrm{~h}$ of one-legged knee extensions (Table I). In a previous study m-LPLA was found to be positively correlated to the excretion of epinephrine in the urine after heavy work (30). However, we have recently shown that one-legged knee extensions cause no increase in m-LPLA during exercise, but that an increase in LPLA is found $4 \mathrm{~h}$ after exercise in the exercised leg but not in the contralateral control leg (31). Furthermore, the increase was transient as it was no longer detectable $8 \mathrm{~h}$ after exercise. Thus, muscle contractions per se cause a delayed, local, and transient increase in m-LPLA.

The relationship between physical training and HDL-C is clear from several longitudinal studies of both sedentary and well trained subjects (e.g., 1-3), and a relationship between $\mathrm{HDL}-\mathrm{C}$ concentration and maximal $\mathrm{VO}_{2}$ has been documented. However, it was recently reported that an increase in HDL-C occurred during increased training in already well trained men without a further increase in maximal $\mathrm{VO}_{2}$ (3). This indicates that local factors play a major role in lipoprotein metabolism. In the present study training did not have any effects on whole body maximal $\mathrm{VO}_{2}$, although peak $\mathrm{Vo}_{2}$ increased in the trained muscle. Nevertheless, $8 \mathrm{wk}$ of intensive dynamic exercise training with one muscle group, weighing on the average $2.5 \mathrm{~kg}$, resulted in a significantly higher $(8 \%)$ HDL-C. This increase is small in absolute terms but is of the same magnitude as reported after moderately intense training of sedentary men (1) and larger than the difference between subjects who have suffered myocardial infarction and those who have not (32). Our findings of changes in systemic HDL-C offer further support for the view that changes in lipoproteins induced by endurance training are caused to a large extent by local adaptations in skeletal muscle.

\section{Acknowledgments}

We are grateful to the subjects who willingly and enthusiastically volunteered for these investigations.

This study was supported by the Danish Heart Foundation, The Research Council of the Danish Sport Federation, the P. A. Brandt Fund, the Swedish Medical Research Council (5460), and the Swedish Sports Medicine Council.

\section{References}

1. Kiens, B., I. Jorgensen, S. Lewis, G. Jensen, H. Lithell, B. Vessby, S. Hoe, and P. Schnohr. 1980. Increased plasma HDL-cholesterol and apo A-I in sedentary middle-aged men after physical conditioning. Eur. J. Clin. Invest. 10:203-209.

2. Lehtonen, A. 1982. Exercise training and serum lipids. In Regulation of Serum Lipids by Physical Exercise. E. Hietanen, editor. CRC Press, Inc., Boca Raton, FL. 71-88.

3. Kiens, B., H. Lithell, and B. Vessby. 1984. Further increase in high density lipoprotein in trained males after enhanced training. Eur. J. Appl. Physiol. Occup. Physiol. 52:426-430.

4. Wood, P. D., and W. L. Haskell. 1979. The effect of exercise on plasma high density lipoproteins. Lipids. 14:417-427.

5. Nye, E. R., K. Carlson, P. Kirstein, and S. Rossner. 1981. Changes in high density subfractions and other lipoproteins induced by exercise. Clin. Chim. Acta. 113:51-57.

6. Patsch, J. R., A. M. Gotto, Jr., T. Olivecrona, and S. Eisenberg. 1978. Formation of high density lipoprotein ${ }_{2}$-like particles during lipolysis of very low density lipoproteins in vitro. Proc. Natl. Acad. Sci. USA. 75:4519-4523.

7. Nikkila, E. A., M.-R. Taskinen, S. Rehunen, and M. Harkonen. 
1978. Lipoprotein lipase activity in adipose tissue and skeletal muscle of runners: relation to serum lipoproteins. Metab. Clin. Exp. 27:1661-1671.

8. Andersen, P., P. R. Adams, G. Sjøgaard, A. Thorboe, and B. Saltin. 1985. Dynamic knee-extension as a model for the study of isolated exercising muscle in man. J. Appl. Physiol. 59:1647-1653.

9. Bergström, J. 1962. Muscle electrolytes in man. Scand. J. Clin. Lab. Invest. 14(Suppl. 68):1-110.

10. Vessby, B., J. Boberg, I.-B. Gustafsson, B. Karlström, H. Lithell, and A.-M. Östlund-Lindqvist. 1980. Reduction of high-density lipoprotein cholesterol and apolipoprotein A-I concentrations by a lipid-lowering diet. Atherosclerosis. 35:21-27.

11. Christensen, N. J., P. Vestergaard, T. Sørensen, and O. J. Rafaelsen. 1980. Cerebrospinal fluid adrenaline and noradrenaline in depressed patients. Acta Psychiatr. Scand. 61:178-182.

12. Lithell, H., and J. Boberg. 1978. Determination of lipoprotein lipase activity in human skeletal muscle tissue. Biochim. Biophys. Acta. 528:58-68.

13. Arner, P., J. Bolinder, P. Engfeldt, and H. Lithell. 1983. The relationship between the basal lipolytic and lipoprotein lipase activities in human adipose tissue. Int. J. Obesity. 7:167-172.

14. Nilsson-Ehle, P., and H. J. Schotz. 1976. A stable radioactive substrate emulsion for assay of lipoprotein lipase. J. Lipid Res. 17:536-541.

15. Andersen, P. 1975. Capillary density in skeletal muscle of man. Acta. Physiol. Scand. 95:203-205.

16. Andersen, P., and B. Saltin. 1985. Maximal perfusion of skeletal muscle in man. J. Physiol. (Lond.). 366:233-249.

17. Svedenhag, J., H. Lithell, A. Juhlin-Dannfelt, and J. Henriksson. 1983. Increase in skeletal muscle lipoprotein lipase following endurance training in man. Atherosclerosis. 49:203-207.

18. Lithell, H., J. Boberg, K. Hellsing, G. Lundquist, and B. Vessby. 1978. Lipoprotein lipase activity in human skeletal muscle and adipose tissue in the fasting and the fed states. Atherosclerosis. 30:89-94.

19. Lithell, H., I. Jacobs, B. Vessby, K. Hellsing, and J. Karlsson. 1982. Decrease of lipoprotein lipase activity in skeletal muscle in man during a short-term carbohydrate-rich dietary regime: with special reference to HDL-cholesterol, apolipoprotein and insulin concentrations. Metab. Clin. Exp. 31:994-998.

20. Kiens, B., B. Essen-Gustavsson, P. Gad, and H. Lithell. 1987. Lipoprotein lipase activity and intramuscular triglyceride stores after long-term high-fat and high-carbohydrate diets in physically trained men. Clin. Physiol. (Oxf.). 7:1-9.

21. Cryer, A. 1981. Review. Tissue lipoprotein lipase activity and its action in lipoprotein metabolism. Int. J. Biochem. 13:525-541.

22. Quinn, D., S. Kohji, and L. Jackson. 1982. Lipoprotein lipase: mechanism of action and role in lipoprotein metabolism. Prog. Lipid. Res. 22:35-78.

23. Olivecrona, T., and G. Bengtsson. 1980. How does lipoprotein lipase bind to substrate lipoproteins and how is its activity regulated? In Atherosclerosis. V. A. M. Gotto, Jr., L. C. Smith, and B. Allen, editors. Springer-Verlag, New York. 393-396.

24. Scow, R. O. 1979. Lipolysis and lipid movement in a membrane model: action of lipoprotein lipase. J. Biol. Chem. 254:64566463.

25. Kiens, B., and B. Saltin. 1985. Enhanced fat oxidation by exercising skeletal muscle after endurance training. Clin. Physiol. (Oxf.). 5(Suppl. 4):86a. (Abstr.)

26. Lithell, H., K. Hellsing, G. Lundquist, and P. Malmberg. 1979. Lipoprotein lipase activity of human skeletal-muscle and adipose tissue after intensive physical exercise. Acta Physiol. Scand. 105:312315 .

27. Lithell, H., J. Orlander, R. Schele, B. Sjodin, and J. Karlsson. 1979. Changes in lipoprotein-lipase activity and lipid stores in human skeletal muscle with prolonged heavy exercise. Acta Physiol. Scand. 107:257-261.

28. Jacobs, I., H. Lithell, and J. Karlsson. 1982. Dietary effects on glycogen and lipoprotein lipase activity in skeletal muscle in man. Acta Physiol. Scand. 115:85-90.

29. Lithell, H., R. Schele, B. Vessby, and J. Jacobs. 1984. Lipoprotein lipase and glycogen after prolonged physical activity. J. Appl. Physiol. 57:698-702.

30. Lithell, H., M. Cedermark, J. Froberg, P. Tesch, and J. Karlson. 1981. Increase of lipoprotein-lipase activity in skeletal muscle during heavy exercise: relation to epinephrine excretion. Metab. Clin. Exp. 30:1130-1134.

31. Kiens, B., H. Lithell, K. Mikines, and E. A. Richter. 1987. Muscle contractions increase and insulin decreases the activity of muscle lipoprotein lipase. Med. Sci. Sports Exercise. 19(Suppl.):452a. (Abstr.)

32. Gordon, T., W. P. Castelli, M. C. Hjortland, W. B. Kannel, and T. R. Dawber. 1977. High-density lipoprotein as a protective factor against coronary heart disease. Am. J. Med. 62:707-714. 